\title{
Penerapan Metode Invers Kinematic pada Rancangan Pergerakan Kaki Robot Humanoid
}

\author{
Fuji Widia ${ }^{1}$, Risfendra ${ }^{2}$ \\ 1,2Jurusan Teknik Elektro, Fakultas Teknik, Universitas Negeri Padang \\ Jl. Prof. Dr. Hamka Air Tawar Padang, Sumatera Barat, 25132, Indonesia \\ fujiw14@gmail.com¹,risfendra@ft.unp.ac.id ${ }^{2}$
}

\begin{abstract}
Humanoid robots are robots that have a human-like skeletal structure, have a head, hands and feet that are designed to be as human-like as possible. For this reason, this robot is also made capable of moving or carrying out activities like humans. Humanoid robot is a fairly complex research, many methods have been applied to humanoid robots. One of them is the inverse kinematic method for the movement of the robot's legs, inverse kinematic can help in modeling the robot movement as needed. Where the inverse kinematic is an analysis method to determine the angle at each joint with the goal and end-effector known. To apply this method, there are applicable provisions that must be followed to ensure the successful application of this method to humanoid robot leg movements. This analysis is made based on the actuator arrangement pattern on the robot, as well as the length between joints and the overall length of the humanoid robot legs, as well as determining the direction of rotation of each joint at the designed angles. This robot uses a dynamixel servo as an actuator with the installation of the skeleton following the Robotis Bioloid type A arrangement and OpenCM-9.04 as the controller. From the test results, the robot can move according to the design movement and the provisions of the servo rotation direction that has been designed, by producing three stages of movement that are initialized upright, stepping and forward. The coordinates of the right foot are in an upright position (0.0, $0.0,0.0)$, stepping $(20.0,10.0,20.0)$, forward (20.0, 10.0, 20.0), while on the left foot an upright position (0.0, 0.0, 0.0), stepping ( $30.0,15.0,20.0)$ and advanced (30.0, 15.0, 20.0).
\end{abstract}

Keywords - Invers Kinematic, Dynamixel Servo, OpenCM-9.04

Abstrak - Robot humanoid merupakan robot yang memiliki struktur kerangka seperti manusia, memiliki kepala, tangan dan kaki yang dirancang semirip mungkin dengan manusia. Untuk itu, robot ini juga dibuat mampu melakukan pergerakan atau melakukan kegiatan seperti manusia. Robot humanoid merupakan penelitian yang cukup kompleks, banyak metode yang telah diterapkan pada robot humanoid. Salah satunya yaitu metode invers kinematic pada pergerakan kaki robot, invers kinematic dapat menbantu dalam pemodelan gerakan robot sesuai dengan yang dibutuhkan. Dimana invers kinematic merupakan metode analisa untuk menentukan besar sudut pada setiap joint dengan tujuan dan end-effector sudah diketahui. Untuk menerapkan metode ini terdapat ketentuan-ketentuan yang berlaku yang harus diikuti untuk membentu keberhasilan penerapan metode ini pada pergerakan kaki robot humanoid. Analisa ini dibuat berdasarkan pola susunan aktuator pada robot, serta panjang antar joint dan panjang keseluruhannya pada kaki robot humanoid, juga menentukan arah putaran setiap joint pada sudut-sudut yang telah dirancang. Robot ini menggunakan dynamixel servo sebagai aktuator dengan pemasangan kerangkan mengikuti pola susunan Robotis Bioloid tipe A dan OpenCM-9.04 sebagai controller. Dari hasil pengujian robot dapat bergerak sesuai rancangan pergerakan dan ketentuan arah putaran servo yang telah dirancang, dengan menghasilkan tiga tahapan gerakan yang diinisialisasikan dengan tegak, melangkah dan maju. Titik koordinat pada kaki kanan dengan posisi tegak $(0.0,0.0,0.0)$, melangkah $(20.0,10.0,20.0)$, maju $(20.0,10.0,20.0)$, sedangkan pada kaki kiri posisi tegak $(0.0,0.0,0.0)$, melangkah $(30.0,15.0,20.0)$ dan maju $(30.0,15.0,20.0)$.

Kata kunci-Invers Kinematic, Servo dynamixel, OpenCM-9.04

\section{Pendahuluan}

Robot merupakan suatu perangkat mekanik yang mampu menjalankan tugas-tugas fisik, baik dibawah kendali dan pengawasan manusia, ataupun yang dijalankan dengan serangkaian program yang telah didefinisikan terlebih dahulu dengan kecerdasan buatan (artificial intelligence)[1]. Penelitian dibidang robotika sudah berkembang pesat[2], robot sudah banyak menggantikan pekerjaan manusia bukan hanya diindustri, namun juga pada kehidupan sehari-hari ada sebagai peramu saji, sebagai peralatan rumah tangga, dan ada juga yang hanya dijadikan sebagai hobi semata. Robot terbagi dalam berbagai jenis, sesuai dengan bentuk, alat gerak dan fungsinya. Berdasarkan alat geraknya robot dibagi menjadi dua macam yaitu robot beroda dan robot berkaki[3]. Salah satu robot berkaki yaitu robot humanoid. Robot humanoid merupakan robot yang dirakit menyerupai manusia yang memiliki kepala, tangan, tubuh, serta kaki dan dibuat mampu melakukan kegiatan seperti manusia serta dapat menyesuaikan diri dengan lingkungan manusia[4].

Pada penelitian ini robot humanoid menerapkan metode invers kinematic pada analisa perancangan pergerakan kaki robot. Robot ini mengikuti aturan perakitan Robotis Bioloid Premium tipe A, dengan aktuator dynamixel servo dengan tiga tipe berbeda yaitu AX-18, Mx- 
28 dan Mx-64, dan controller yang digunakan adalah OpenCM-9.04. Metode invers kinematic ini merupakan metode analisa untuk dapat menentukan besar sudut pada setiap joint dengan nilai end-effector sudah diketahui [5].

Analisa metode invers kinematic akan ditentukan sesuai dengan ukuran dan bentuk kaki robot agar dapat menentukan arah putaran dynamixel servo yang digunkaan sebagai aktuator robot. Alat ini berfokus pada pergerakan kaki robot humanoid menggunakan struktur perakitan Robotis Bioloid tipe A, dengan frame yeng terbuat dari plat aluminium setebal $1.5 \mathrm{~mm}$. untuk peneraran metode invers kinematic ini sangat dibutuhkan ketepatan ukuran dari kaki robot humanoid yang akan digunakan, ukuran ini diperoleh dari panjang antara joint pada kaki robot humanoid yang ditandai dengan titik biru pada gambar 4 . Selain ukuran dari antar joint, pemasangan dinamixel servo juga harus dipastikan sesuai dengan kebutuhan gerakan kaki pada robot. Jika ada kesalah dalam pemasangan dynamixel servo pada kaki robot maka akan mengakibatkan banyaknya error dari gerakan.

Dengan menerapkan metode invers kinematic pada robot humanoid yang menggunakan dynamixel servo sebagai actuator, analisa pergerakan robot tidak hanya bergantung pada pemasangannya pada robot tapi juga harus memperhatikan arah putaran servo. Karna dengan menentukan arah putaran yang sesuai dengan gerakan yang dibutuhkan akan menjadi acuan untuk analisa batasan pergerakan dan betuk gerakan yang akan dibentuk oleh kaki robot. Nantinya akan diinputkan pada program pergerakan robot yang sudah menerapkan metode invers kinematic. Dengan menerapkan metode invers kinematic panjang dari masing-masing joint bila diubah tidak akan menyebabkan gerakan robot menjadi kacau. Panjang joint dapat disesuaikan dengan kebutuhan serta dapat diganti kapan saja tanpa mempengaruhi struktur program, sehingga robot dapat bergerak tetap dapat bergerak seperti yang telah dirancang sebelumnya.

\section{Metode}

\section{A. Robot Humanoid}

Robot humanoid merupakan robot yang memiliki struktur kerangka seperti manusia, memiliki kepala, tangan dan kaki yang dirancang semirip mungkin dengan manusia. Untuk itu, robot ini juga dibuat mampu melakukan pergerakan atau melakukan kegiatan seperti manusia[6]. Robot humanoid sudah banyak beredar dipasaran seperti Robotis Bioloid Premium. Robotis Bioloid Premium merupakan produk buatan Korea Selatan yang sudah tidak asing lagi dikalangan penggiat robot. Robot Bioloid Premium adalah kit robot pendidikan do-it-yourself (DIY) dari Robotis yang menggunakan blok aktuator servo Dynamixel modular [7]. Robotis menyediakan robot ini untuk penggemar robot, menginspirasi penggiat robotika, dan mereka yang memiliki pikiran kreatif. Premium Bioloid hadir dalam kit robot lengkap dengan instruksi untuk perakitan robot humanoid, anjing, dinosaurus, droid probing, kura-kura, robot penggali, dan bahkan laba-laba. Robot DIY juga mampu diubah dari robot humanoid biped menjadi robot beroda dan robot hexapod. Pada Robotis Bioloid memiliki tiga tipe perakitan robot yang dinamanakan dengan tipe A, tipe B dan tipe C. perbedaain pada setiap tipe terdapat pada jumlah dan letak dari dynamixel servo yang dirakit yang dapat dilihat pada gambar 1, 2, dan 3 .

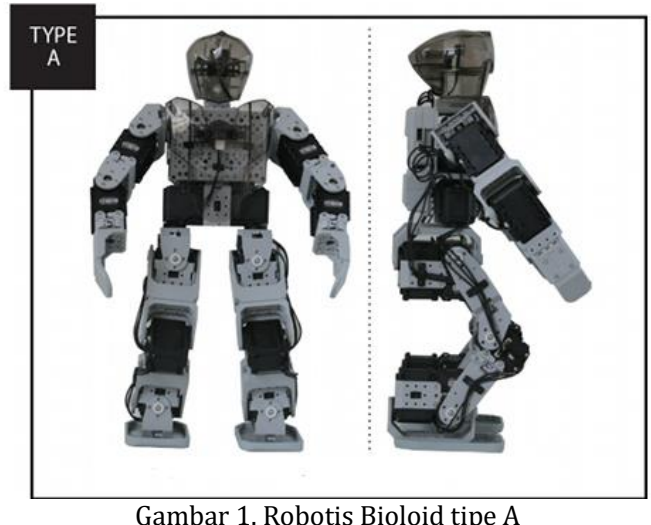

Perbedaan signifikan dari semua tipe terdapat pada kaki bagian atas, yaitu pangkal paha. Pada tipe A pangkal pada dapat melakukan gerakan berputar, dapat bergerak kekiri dan kekanan, dan dapat bergerak kedepan dan kebelakang. Dari tiga tipe yang ada tipe A dapat melakukan lebih banyak mode gerakan, sehingga tipe ini banyak digunakan oleh para penggiat robotika. Namun pada tipa juga menggunakan dynamixel servo lebih banyak dari tipe B dan tipe $C$.

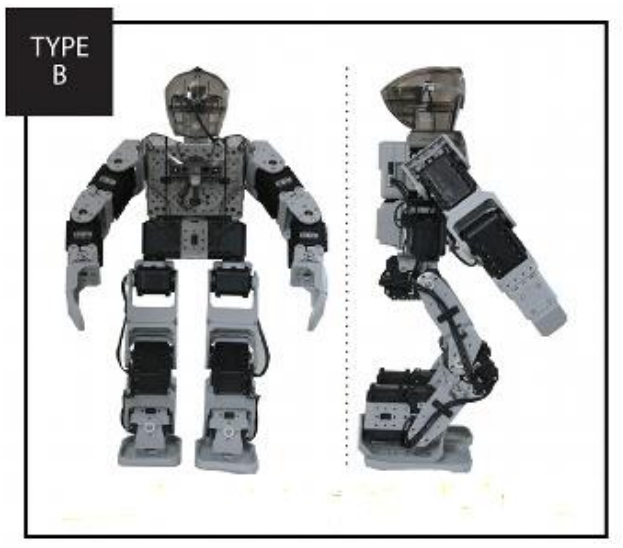

Gambar 2. Robotis Bioloid tipe B

Pada gambar 2 diatas dapat dilihat bentuk susunan dynamixel servo pada Robotis Bioloid tipe B. Tipe B pangkal paha dapat bergerak berputar dan dapat bergerak kedepan dan kebelakang. Pada ripe ini tidak dapat melakukan gerakan kekiri dan kekanan seperti pada tipe A. 


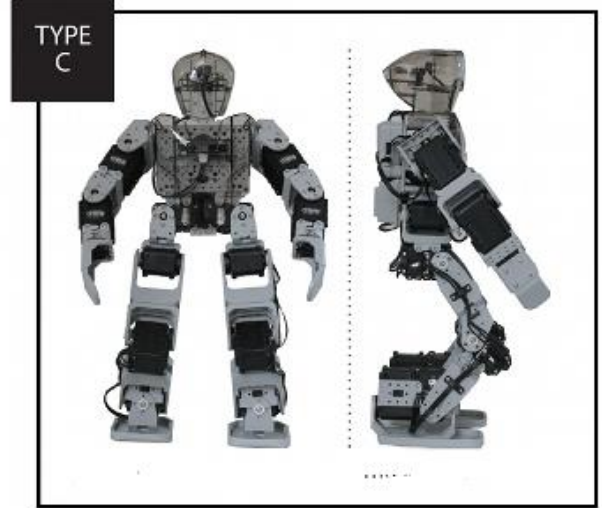

Gambar 3. Robotis Bioloid tipe C

Pada tipe $\mathrm{C}$ yang dapat dilihat pada gambar 3 , bagian pangkal paha tidak dapat bergerak memutar seperti pada tipe A dan tipe B. Pergerakan yang dapat dilakukan pada Robotis Bioloid tipe $\mathrm{C}$ hanya dapat melakukan gerakan kedepan dan kebelakang, serta gerakan kekiri dan kekanan. Gerakan yang dapat dilakukan oleh masing-masing tipe dipengaruhi oleh arah horn dari dynamixel servo yang digunakan, horn ini dihubungkan dengan frame pada robot. Sama halnya dengan persendian pada manusia [8].

\section{B. Diagram Blok}

Pad alat ini menerpakan métode invers kinematik yang diterapkan sebagai método yang dapat menyesuaikan dengan bentuk serta ukuran robot tanpa merusak gerakan yang sudah dirancang. Selain itu método invers kinematic juga digunakan untuk analisa pergerakan pada kaki robot menjadi lebih otomatis tidak manual lagi [9].

Alat ini menggunakan controller OpenCM-9.04, sebagai pengolah data pada robot humanoid. Pada OpenCM-9.04 sebagai pengontrol utama pada robot, seluruh program yang dibuat akan dimuat di controller ini. Analisa invers kinematikc akan diproses disini, setelah data analisa pergerakan diproses maka data tersebut akan dikirimkan pada aktuator robot. Aktuator robot humanoid yang dirancang menggunakan dynamixel servo seperti aktuator penyusun Robotis Bioloid Premium dan beberapa dynamixel servo lainnya yang telah di upgrade.

Dynamixel servo yang digunakan pada alat ini terdiri dari tiga tipe servo yaitu, dinamixel servo AX-18, dinamixel servo MX-28 dan dinamixel servo MX-64. Ketiga dinamixel servo ini diletakkan pada posisi yang berbeda, untuk memmaksimalkan kinerja dari robot. Dynamixel servo digunakan sebagai aktuator atau penggerak pada robot dipenelitian ini, pada masing-masing servo diterapkan invers kinematic. Untuk menandai sudut-sudut yang telah dibuat pada perancangan maka disetiap servo diinisialisasikan dengan $\alpha, \beta, \gamma, \theta$, dan $\omega$. Sementara itu untuk membedakan kakan dan kiri ditambahkan left dan right. Servo pinggang robot diatur pada posisi center atau titik tengah saja sehingga pada perubahan nilai koordinat, tidak akan berpegaruh pada posisinya. Dynamixel servo
AX-18 diinisialisasikan dengan $\alpha \_r i g h t, \alpha \_l e f t, \omega \_r i g h t$, dan $\omega_{-}$left. Dynamixel servo MX-28 diinisialisasikan dengan $\theta_{-}$right, $\theta_{-}$left, $\gamma_{-}$right dan $\gamma_{-}$left. Dynamixel servo MX-64 diinisialisasikan dengan $\beta_{-}$right dan $\beta_{-}$left. Untuk lebih jelasnya dapat dilihat pada diagram blok pada gambar 4 .

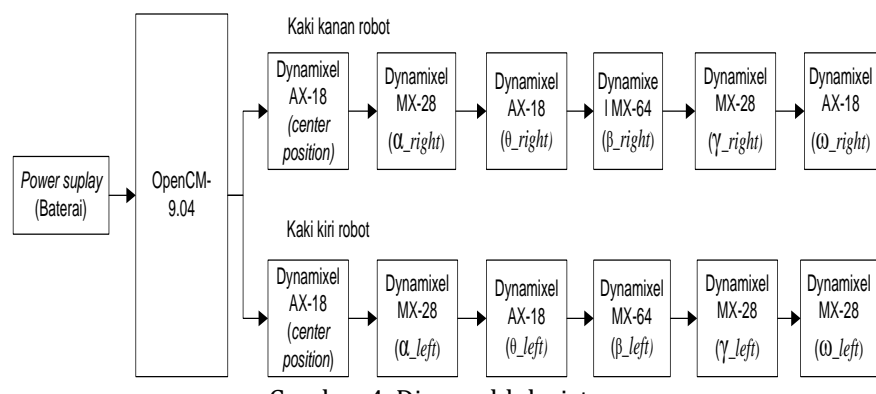

\section{Flowchart}

Prinsip kerja alat secara keseluruhan dibuat dalam bentuk diagram alir atau disebut juga dengan flowchart. Dengan ini prosesi dari progam akan digambarkan dari awal program dijalankan hingga akhir dari program, yang dituangkan dalam bentuk gambar atau simbol-simbol [10]. Hal ini berguna untuk membantu programer memecahkan masalah kedalam segmen yang lebih kecil. Flowchart sistem keseluruhan dapat dilihat pada gambar 5 .

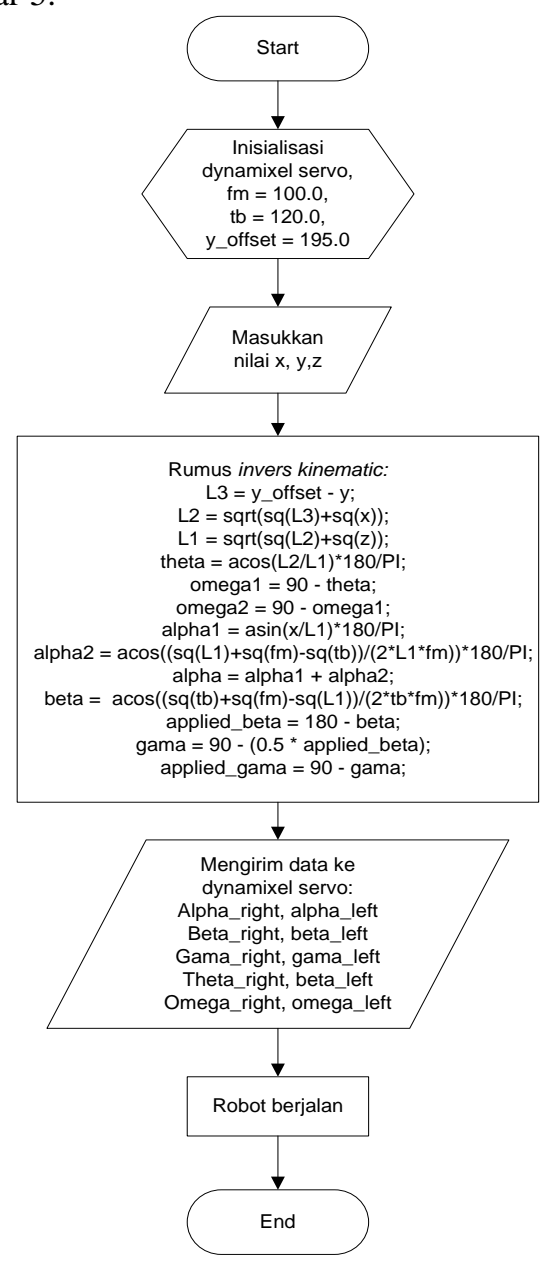


Gambar 5. Flowchart sistem keseluruhan

\section{Rancangan Software}

Perancangan software secara keseluruhan pada tugas akhir ini menggunakan Robotis_OpenCM, yaitu software buatan Robotis untuk memprogram OpenCM-9.04 yang digunakan sebagai kontroler dari robot humanoid yang dirancang. Pada software Robotis_OpenCM programer akan menuliskan kode program dengan algoritma-algoritma yang dibutuhkan dari penerapan metode invers kinematic. Visualisasi invers kinematic kerangka pada kaki robot dapat dilihat pada gambar 6.

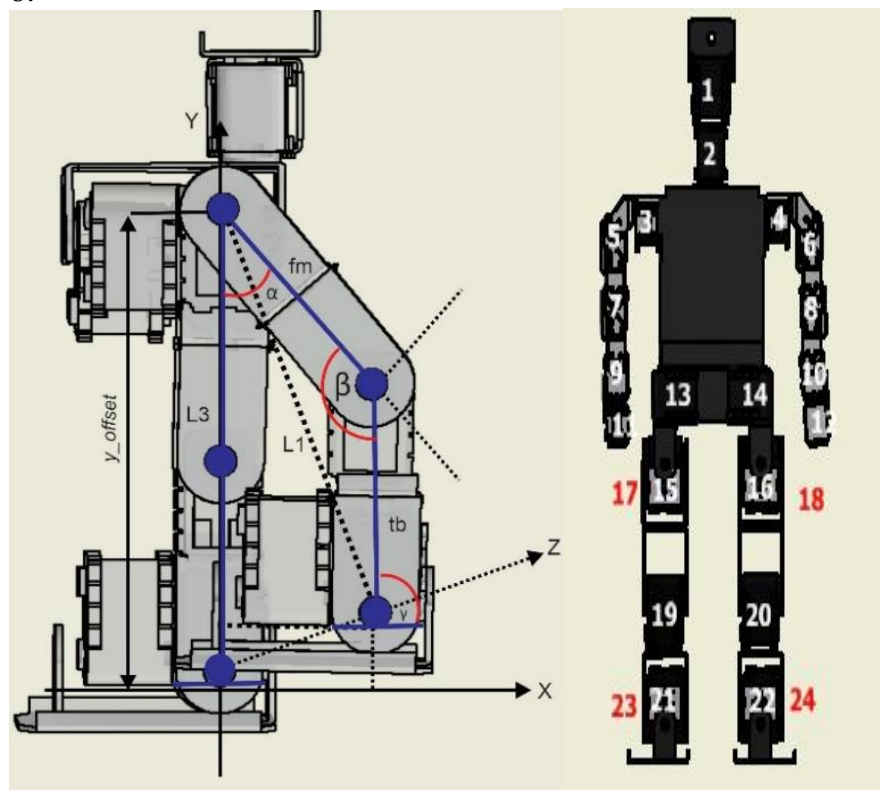

Gambar 6. Visualisasi penerapan invers kinematic dan ID servo

Panjang kaki robot diukur antara joint pada gambar 6 ditandai dengan bulatan berwarna biru. Untuk panjang joint dikaki bagian atas diinisialisasikan dengan fm (femur lenght) dengan panjang $10 \mathrm{~cm}$. Panjang antara joint pada kaki bagian bawah diinisialisasikan dengan tb (tibia lenght) panjangnya adalah $12 \mathrm{~cm}$. Sedangkan panjang keseluruhan dari keduanya diinisialisasikan dengan $y_{-}$offset.

Seperti yang telah dijelaskan sebelumnya, bahwa robot humanoid yang dirancangan menerapkan tipe rancangan Robotis Bioloid tipa A. Pada bagian pinggang yang jika dilihat pada gambar 6 , servo pada bagian paling atas yang difungsikan untuk memutar kaki, namun untuk gerakan jalan servo ini akan diaktifkan pada center position yaitu posisi tengah dengan ID 13 pada kaki kanan dan 14 pada kaki kiri. Servo yang digunakan adalah dynamixel servo AX18. Yang ditandai dengan $\alpha$ difungsikan sebagai persendian pangkal paha, mengangkat kaki dari bagian atas kedepan. Servo yang digunakan adalah servo dynamixel MX-28 dengan ID 15 pada kaki kanan dan 16 pada kaki kiri. Pada persendian lutut diinisialisasikan dengan $\beta$, difungsikan untuk gerakan kaki dilipat dan diluruskan layaknya sendi manusia. Servo yang digunakan pada bagian ini adalah dynamixel servo MX-64 dengan ID 19 di kaki kanan dan 20 dikaki kiri. Sementara pada bagian mata kaki robot diinisialisasikan dengan $\gamma$, difungsikan untuk persendian pergerlangan kaki yang dapat bergerak keatas dan kebawah. Servo yang digunakan adalah dynamixel MX-28, dengan ID 21 pada kaki kanan dan 22 pada kaki kiri. Konfigurasi invers kinematic yang diterapkan pada robot humanoid ini, lebih lengkapnya dapat dilihat pada gambar 7 dan 8.

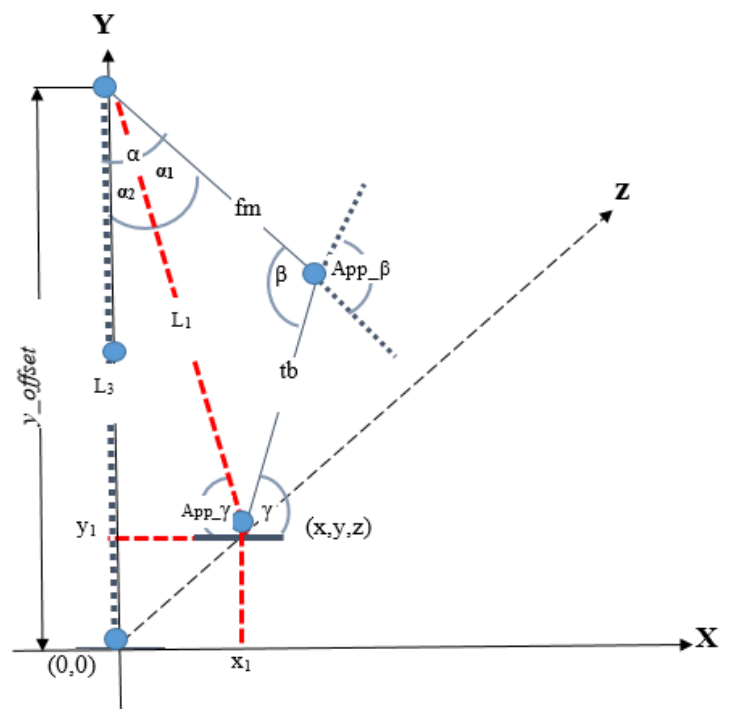

Gambar 7. Konfigurasi invers kinematic kaki robot tampak samping

Pada konfigurasi invers kinematik diatas dapat diperoleh persamaan untuk mendapatkan nilai dari sudut $\alpha, \beta$, dan $\gamma$ yang dibutuhkan untuk pergerakan jalan robot. Untuk itu dapat menggunakan persamaan (1-6). Terdapat tiga nilai yang konstan pada konfigurasi ini yaitu nilai dari $\mathrm{fm}$ (femur lenght), tb (tibia lenght) dan $y_{-}$offset. Ketiga nilai ini merupakan ukuran dari antar joint dan panjang keseluruhan pada kaki robot, yang dapat diubah sesuai ukuran kaki robot tanpa merusak gerakan yang telah dirancang.

$L_{3}=y-o f f$ set $-y$
$L_{2}=\sqrt{{L_{3}}^{2}+y^{2}}$
$L_{1}=\sqrt{L_{2}^{2}+z^{2}}$
$\alpha_{1}=\sin ^{-1}\left(x-L_{1}\right) \times 180 / P I$
$\alpha_{2}=\cos ^{-1}\left\{\frac{L_{1}^{2}+f m^{2}-t b^{2}}{2 \times L_{1} \times f m}\right\} \times\left(\frac{180}{P I}\right)$
$\alpha=\alpha_{1}+\alpha_{2}$

Setelah mendapatkan nilai $\alpha$, selanjutnya untuk memperoleh nilai sudut $\beta$ dapat menggunakan persamaan (7-10).

$\beta=\cos ^{-1}\left\{\frac{t b^{2}+f m^{2}-L_{1}^{2}}{2 \times t b \times f m}\right\} \times\left(\frac{180}{P I}\right)$

$\operatorname{app}_{\beta}=180-\beta$

$\gamma=90-\left(0.5 \times a p p_{-} \beta\right)$

$a p p_{\gamma}=90-\gamma$ 
Untuk memaksimalkan penerapan invers kinematic pada pergerakan jalan robot maka dibuatlah konfigurasi seperti pada gambar 8 .

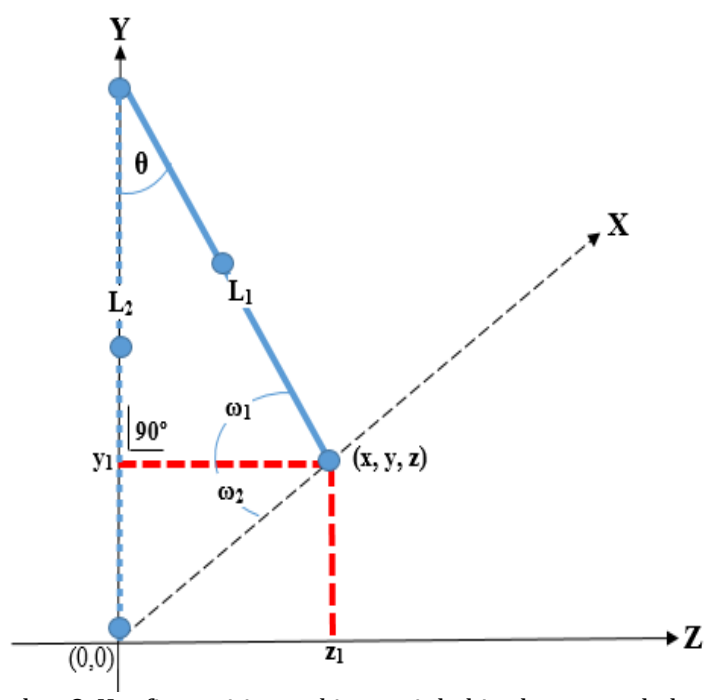

Gambar 8. Konfigurasi invers kinematic kaki robot tampak depan

Pada konfigurasi pada gambar 8 dapat diperoleh persamaan (11-13) untuk memperoleh nilai sudut $\theta$ dan $\omega$.

$$
\begin{aligned}
& \theta=\cos ^{-1}\left(\frac{L_{2}}{L_{1}}\right) \times\left(\frac{180}{P I}\right) \\
& \omega_{1}=90-\theta \\
& \omega_{2}=90-\omega_{1}
\end{aligned}
$$

Dengan menerapkan metode invers kinematic dengan konfigurasi seperti gambar 7 dan gambar 8, maka kita dapat menentukan konvigurasi dari sudut dynamixel servo yang akan digunakan pada robot seperti gambar 9.

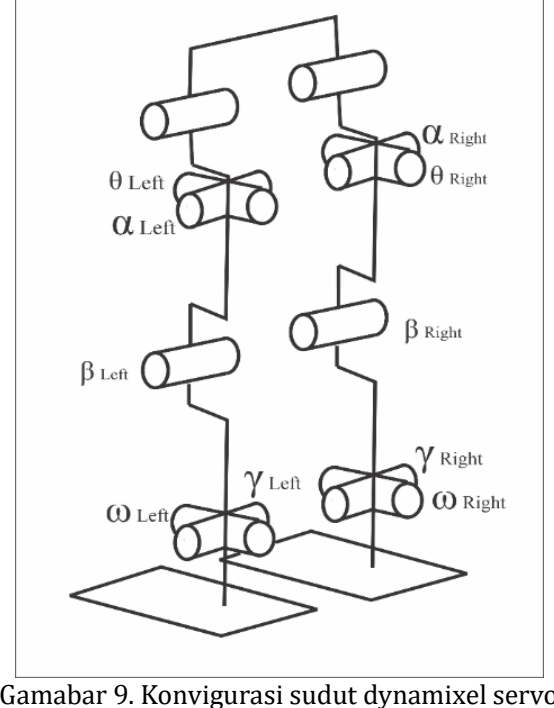

\section{E. Rancangan Hardware}

Perancangan hardware merupakan tahapan untuk membuat gambaran perangkat keras dari alat pada tugas akhir ini. Perancangan hardware bertujuan untuk memudahkan serta mengurangi tingkat kesalahan dalam membuat perangkat keras sehingga mendapatkan hasil yang optimal [11]. Rangkain keseluruhan yangakan digunakan pada robot dapat dilihat pada gambar 9 .

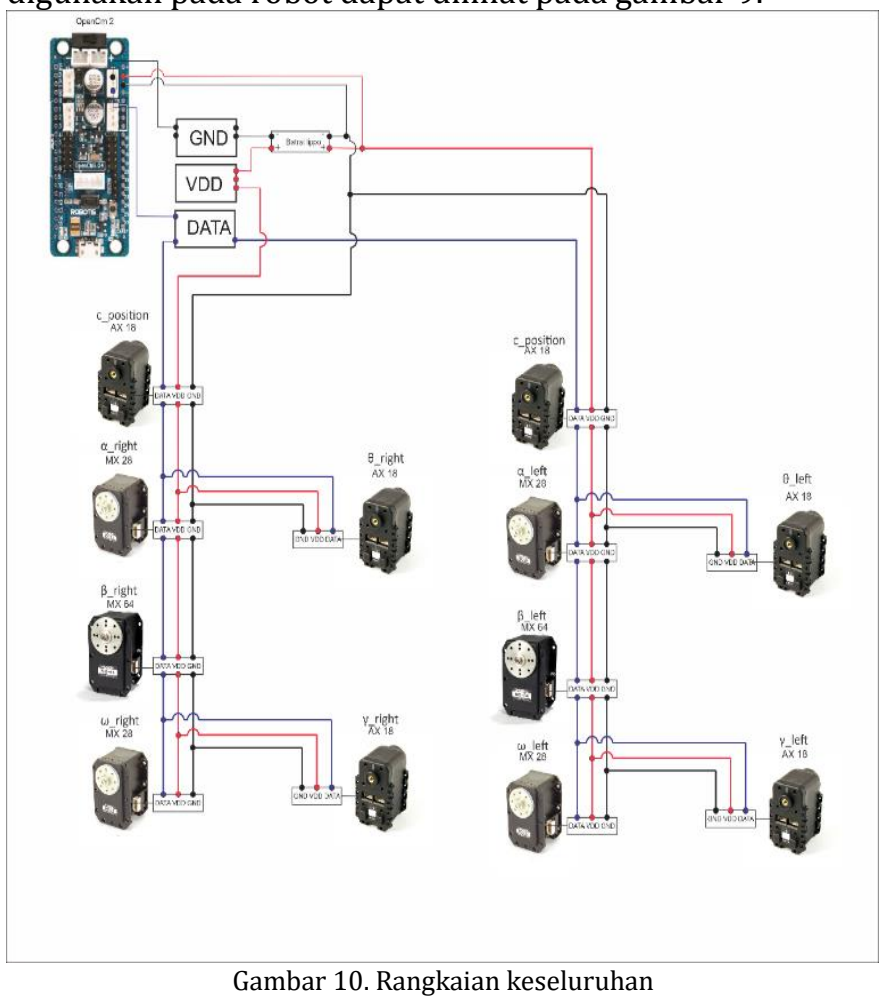

III. HASIL DAN PEMBAHASAN

Pada bagian ini dilakukan pegujian dan analisa dari perancangan yang telah dibut. Pengujian pertama dilakukan secara mekanikal yang bertujuan untuk membandingkan rancangan mekanikyang sudah dibuat sebelumnya. Dengan pengujian mekanik ini kita dapat melihat apakal alat yang dibuat sudah berjalan dengan baik dan apakah telah sesuai dengan yang diharapkan. Pada perancangan alat ini menggunakan microcontroller OpenCM-9.04 sebagai pengontrol utama dari alat ini. Seperti yang sudah dibahas sebelumnya alat ini menggunakan dynamixel servo sebagai aktuator robot dengan tiga tipe yang berbeda. Perancangan alat ini dibuat berupa robot humanoid yang dirakit menggunakan frame dari bahan plat aluminium setebal $1.5 \mathrm{~mm}$ yang dapat dilihat pada gambar 4 .

Selanjutnya pengujian dan analisa putaran dynamixel servo yang digunakan pada robot. Metode invers kinematic yang diterapkan pada pergerakan robot untuk memastikan apakah metode ini dapat mengatasi perubahan pada body robot sehingga dapat tetap bergerak sesuai dengan rancangan gerakan yang dibutuhkan. Seperti pada alat ini diujikan pada gerakan jalan robot. Metode ini dianalisa dengan formula-formula yang dibuat berdasarkan pendekatan trigonometri. Dimana trigonometri mengacu pada segitiga, yang sama-sama kita ketahui segitiga 
memiliki tiga sudut dengan besar sudut keseluruhannya adalah $180^{\circ}$. Dynamixel servo berputar dengan derjat kebebasan yang memiliki batasan $0^{\circ}-300^{\circ}$ untuk dynamixel servo tipe AX-18 dan $0^{\circ}-360^{\circ}$ untuk dynamixel servo tipe MX, untuk lebih jelas dapat dilihat pada gambar 10.

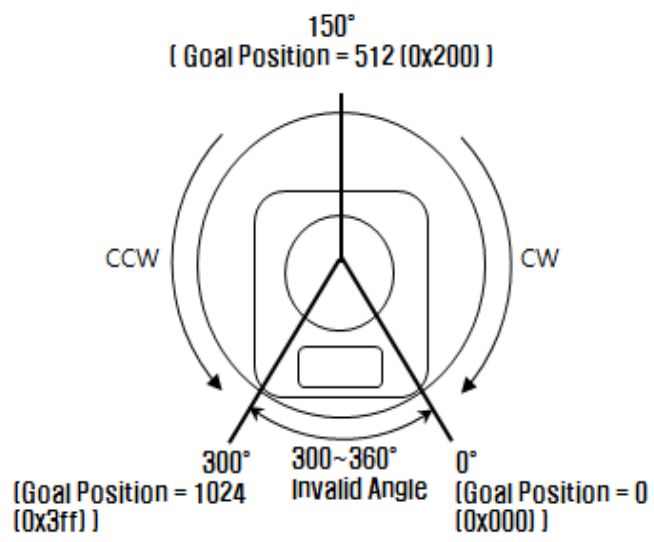

Gambar 11. Goal position dynamixel servo

Dynamixel servo memiliki nilai tersendiri yang menandai pergerakannya nilai ini diperoleh dari titik-titik yang mengitari putaran servo atau sering disebut dengan goal position. Semisal nilai center position dynamixel servo $\mathrm{AX}$ adalah 512 pada $150^{\circ}$ dan center position untuk tipe dynamixel servo yaitu 2047 pada $180^{\circ}$. Dynamixel servo berputar dengan derjat kebebasan yang memiliki batasan $0^{\circ}-300^{\circ}$ untuk dynamixel servo tipe AX-18 dan $0^{\circ}-360^{\circ}$ untuk dynamixel servo tipe MX, untuk lebih jelas dapat dilihat pada gambar 10 .

Dynamixel servo memiliki nilai tersendiri yang menandai pergerakannya nilai ini diperoleh dari titik-titik yang mengitari putaran servo atau sering disebut dengan goal position. Semisal nilai center position dynamixel servo AX adalah 512 pada $150^{\circ}$ dan center position untuk tipe dynamixel servo yaitu 2047 pada $180^{\circ}$. Untuk mengkonversi data dari dynamixel servo dapat menggunakan persamaan 14 .

$\alpha=\frac{\text { nilai satu putaran }(\text { goal position })}{\text { batas derjat kebebasan servo }}$

Agar dynamixel servo dapat memproses data yang diperoleh dari invers kinematic, dapat menggunakan persamaan 14. Berikut penyelesaianya:

$$
\begin{aligned}
\text { MX series center position } & =2047 \\
0 / C W & =0 \\
360 / C C W & =4095 \\
\alpha=\frac{4095}{360} & =11.375^{\circ} \\
A X \text { series center position } & =512 \\
0 / C W & =0 \\
300 / C C W & =1023 \\
\alpha=\frac{1023}{300} & =3.41^{\circ}
\end{aligned}
$$

Dari penyelesaian diatas maka diperoleh nilai untuk satu derjat putaran dynamixel servo tipe MX adalah 11.375 pada goal position, sedangkan nilai satu derjat putaran dynamixel servo tipe AX yaitu 3.41 pada goal position.

Selanjutanya pengujian dan analisa pada pergerakan jalan robot, pengujian dilakukan dengan menghubungkan dynamixel servo dengan microkontroler dan baterai, $12 \mathrm{~V}$ dihubungkan untuk dynamixel servo dan $7.4 \mathrm{~V}$ untuk openCM-9.04. Ada tiga tahapan jalan yang dirancang pada robot yaitu saat kaki tegak (walready). Posisi tegak diranang dengan lutut robot ditekuk serta mata kaki dan bokong disejajarkan. Kemudian posisi kaki melanngkah, dimana kaki kanan diangkat dan dimajukan sekaligus, dan untuk keseimbangan kaki kiri agak dimiringkan. Terakhir ada posisi terakhir dinamakan maju, dimana posisi kaki kanan menapak kembali dengan osisi lebih maju dari kaki kiri dan kaki kiri kembali di posisi walkready. Sebelum pengujian untuk gerakan kaki robot kita harus mengetahui koordinat $\mathrm{x}, \mathrm{y}$, dan $\mathrm{z}$ yang telah dirancang untuk pergerakn robot yang dapat dilihat pada tabel 1 .

TABEL I. NILAI KOORDINAT X,Y, DAN Z

\begin{tabular}{|c|c|c|c|c|}
\hline Kaki & Posisi & $\mathrm{X}(\mathrm{mm})$ & $\mathrm{Y}(\mathrm{mm})$ & $\mathrm{Z}(\mathrm{mm})$ \\
\hline \multirow{3}{*}{ Kanan } & Tegak & 0.0 & 0.0 & 0.0 \\
\cline { 2 - 5 } & Melangkah & 20.0 & 10.0 & 20.0 \\
\cline { 2 - 5 } & Maju & 20.0 & 10.0 & 20.0 \\
\hline \multirow{3}{*}{ Kiri } & Tegak & 0.0 & 0.0 & 0.0 \\
\cline { 2 - 5 } & Melangkah & 30.0 & 15.0 & 20.0 \\
\cline { 2 - 5 } & Maju & 30.0 & 15.0 & 20.0 \\
\hline
\end{tabular}

Adapun nilai perhitungan dari invers kinematic pada masing-masing sudut yang telah dirancang dapat dilihat pada tabel II untuk kaki kanan dan tabel III untuk kaki kiri.

TABEL II. INVERS KINEMATIC PADA KAKI KANAN

\begin{tabular}{|c|l|l|l|l|l|}
\hline Posisi kaki & d_right & $\beta_{-}$right & $\gamma_{-}$right & $\theta_{-}$right & $\omega_{-}$right \\
\hline Tegak & 2343 & 1369 & 2345 & 485 & 490 \\
\hline Melangkah & 2465 & 1275 & 2392 & 505 & 510 \\
\hline Maju & 2465 & 1275 & 2392 & 505 & 510 \\
\hline
\end{tabular}

TABEL III. INVERS KINEMATIC PADA KAKI KIRI

\begin{tabular}{|c|l|l|l|l|l|}
\hline Posisi kaki & $\alpha \_l e f t$ & $\beta \_l e f t$ & $\gamma_{-}$left & $\theta_{-}$left & $\omega_{-}$left \\
\hline Tegak & 1750 & 2724 & 1748 & 545 & 515 \\
\hline Melangkah & 1568 & 2858 & 1681 & 523 & 493 \\
\hline Maju & 1568 & 2858 & 1681 & 523 & 493 \\
\hline
\end{tabular}

Nilai x, y dan z yang diinputkan pada program, ini akan membuat perubahan pada gerakan robot, nilai $\mathrm{x}$ akan membuat perubahan pada sudut $\alpha, \beta, \gamma$ yang akan membentuk gerak maju pada kaki robot. Nilai y akan memberikan perubahan pada sudut $\alpha, \beta, \gamma$ yang akan membuat robot mengangkat kaki sesuai koordinat yang diinputkan. Sementara nilai koordinat z akan memberikan 
pengaruh pada nilai sudut $\theta$ dan $\omega$ yang akan memberikan pengaruh pada posisi miring dari kaki robot $\theta$ untuk kaki bagian atas dan $\omega$ untuk kaki bagian bawah. Pada table IV dapat dilihat gerakan yang dibuat dengan menggunakan metode invers kinematic.

TABEL IV. IMPLEMENTASI GERAKAN PADA KAKI ROBOT

\begin{tabular}{|c|c|c|}
\hline No. & Posisi & Bentuk gerakan \\
\hline 1 & Tegak & \\
\hline 2 & Melangkah & \\
\hline 3 & Maju & \\
\hline
\end{tabular}

\section{Pengaruh Tipe Kaki dan Tinggi Robot Humanoid pada}

\section{Penerapan Metode Invers Kinematic}

Robotis Bioloid memiliki tiga tipe perakitan robot humanoid, seperti yang telah dijelaskan sebelunya. Terdapat tiga tipe yaitu tipe $\mathrm{A}$, tipe $\mathrm{B}$, dan tipe $\mathrm{C}$ yang memiliki perbedaan pada susunan servo pada kaki bagaian atas robot. Susunan servo ini akan menmpengaruhi pergerakan dari robot, tipe A memiliki kelebihan dengan dapat melakukan tiga gerakan pada kakibagian atas atau bisa disebut persendian pada bagian paha, dibandingkan dengan dua tipe lainnya yang hanya dapat melakukan dua gerakan.

Metode invers kinematik pada analisa pergerakan kaki robot humanoid, dapat disesuaikan dengan bentuk robot yang kita butuhkan. Dengan menerapkan metode ini kita dapat menentukan bagaimana robot akan bergerak, gerakan apa saja yang dibuthkan oleh robot, serta servo apa saja yang dibutuhkan untuk pergerakan tersebut dengan kata lain kita membuat robot tau harus bergerak kemana. Pada penelitian yang telah dilakukan sebelum oleh Ahmad Iqbal pada penelitiannya yang membahas evaluasi invers kinematic, metode ini juga digunakan untuk keseimbangan robot quardruped.

Pada penelitian ini menerapkan tipe A, pada perakitan robot dengan tinggi tobot yang bertikai $\pm 10 \mathrm{~cm}$. Panjag kaki robot dibagi menjadi dua bagian yaitu kaki bagian atas $\mathrm{fm}=$
$10 \mathrm{~cm}$ dan kaki bagian bawah tb $=12 \mathrm{~cm}$. Panjang kaki robot sangat mempengaruhi analisa dari pergerakan kaki dengan metode invers kinematic, jika ukuran panjang kaki tidak sesuai dengan robot yang digunakan, maka pergerakan yang dirancang pada robot tidak akan singkron. Panjang kaki robot diukur dari antar joint yang dapat dilihat pada gambar 4 yang ditandai dengan titik biru. Namun ukurun ini dapat diganti kapanpun sesuai kebutuhan tanpa mengubah analisa rancangan pergerakan lainnya. Pergerkan yang dirancang dengan invers kinematic dapat dilihat pada gambar 7 dan gambar 8. Untuk arah putaran dari servo dynamixel yang digunakan pada robot dapat dilihat pada tabel V.

\section{TABEL IV. IMPLEMENTASI METODE INVERS KINEMATIK TERHADAP DYNAMIXEL SERVO PADA KAKI ROBOT}

\begin{tabular}{|c|c|c|c|c|}
\hline No. & Posisi kaki & $\begin{array}{l}\text { Arah } \\
\text { putaran } \\
\text { dynamixel } \\
\text { servo }\end{array}$ & Visualisasi & Arah aksis \\
\hline 1. & $\begin{array}{l}\text { Pinggang } \\
\text { kanan, horn } \\
\text { menghadap } \\
\text { Kebawah }\end{array}$ & $\begin{array}{l}\text { Ditetapkan } \\
\text { pada center } \\
\text { position }\end{array}$ & & - \\
\hline 2. & $\begin{array}{l}\text { Pinggang kiri, } \\
\text { horn } \\
\text { menghadap } \\
\text { kebawah }\end{array}$ & $\begin{array}{l}\text { Ditetapkan } \\
\text { pada center } \\
\text { position }\end{array}$ & & - \\
\hline 3. & $\begin{array}{l}\text { Paha kanan, } \\
\text { horn } \\
\text { menghadap } \\
\text { kekanan }\end{array}$ & $\begin{array}{l}\text { Dari center } \\
\text { position, } \\
\text { servo akan } \\
\text { berputar } \\
\text { berlawanan } \\
\text { arah jarum } \\
\text { jam. }\end{array}$ & & $\operatorname{lig}_{\alpha_{\text {Right }}}^{2} x$ \\
\hline 4. & $\begin{array}{l}\text { Paha kiri, } \\
\text { horn } \\
\text { menghadap } \\
\text { kekiri }\end{array}$ & $\begin{array}{l}\text { Dari center } \\
\text { position, } \\
\text { servo akan } \\
\text { berputar } \\
\text { searah } \\
\text { jarum jam. }\end{array}$ & & $\underset{\alpha_{\text {Left }}}{2}$ \\
\hline 5. & $\begin{array}{l}\text { Bokong } \\
\text { kanan, horn } \\
\text { membelakingi } \\
\text { servo paha }\end{array}$ & $\begin{array}{l}\text { Dari center } \\
\text { position, } \\
\text { servo akan } \\
\text { berputar } \\
\text { berlawanan } \\
\text { arah jarum } \\
\text { jam. }\end{array}$ & & ${\underset{\theta \text { Righ }}{\longrightarrow}}^{x} z$ \\
\hline 6. & $\begin{array}{l}\text { Bokong kiri, } \\
\text { horn } \\
\text { membelakingi } \\
\text { servo paha }\end{array}$ & $\begin{array}{l}\text { Dari center } \\
\text { position, } \\
\text { servo akan } \\
\text { berputar } \\
\text { searah } \\
\text { jarum jam. }\end{array}$ & & $\rightarrow 2$ \\
\hline 7. & Lutut kanan & $\begin{array}{l}\text { Dari center } \\
\text { position, } \\
\text { servo akan } \\
\text { berputar } \\
\text { searah } \\
\text { jarum jam. }\end{array}$ & & $\int_{\beta \text { Righe }}^{\longrightarrow} x$ \\
\hline 8. & Lutut kiri & $\begin{array}{l}\text { Dari center } \\
\text { position, } \\
\text { servo akan } \\
\text { berputar } \\
\text { berlawanan }\end{array}$ & & $\beta$ йt \\
\hline
\end{tabular}




\begin{tabular}{|c|l|l|l}
\hline 9. & $\begin{array}{l}\text { arah jarum } \\
\text { jam. }\end{array}$ \\
\hline Manan kaki & $\begin{array}{l}\text { Dari center } \\
\text { position, } \\
\text { servo akan } \\
\text { difungsikan } \\
\text { berputar } \\
\text { dua arah } \\
\text { sesuai } \\
\text { kebutuhan. }\end{array}$ \\
\hline 10. & Mata kaki kiri & $\begin{array}{l}\text { Dari center } \\
\text { position, } \\
\text { servo akan } \\
\text { difungsikan } \\
\text { berputar } \\
\text { dua arah } \\
\text { sesuai } \\
\text { kebutuhan. }\end{array}$ \\
\hline 11. & Tumit kanan & $\begin{array}{l}\text { Dari center } \\
\text { position, } \\
\text { servo akan } \\
\text { difungsikan } \\
\text { berputar } \\
\text { dua arah } \\
\text { sesuai } \\
\text { kebutuhan. }\end{array}$ \\
\hline 12. & $\begin{array}{l}\text { Dari center } \\
\text { position, } \\
\text { servo akan } \\
\text { difungsikan } \\
\text { berputar } \\
\text { dua arah } \\
\text { sesuai } \\
\text { kebutuhan. }\end{array}$ \\
Tumit kiri
\end{tabular}

\section{PenutuP}

Setelah melakukan pengujian penerapan invers kinematic pada pergerakan jalan robot humanoid, maka dapat diambil kesimpulan yaitu, analisa perancangan gerakan jalan robot dapat diimplementasikan pada robot. Robot menggunakan struktur perakitan Robotis Bioloid tipe A. Gerakan robot dibuat berdasarkan analisa metode invers kinematic yang menghasilkan tiga gerkan yang diinisialisasikan dengan tegak, melangkah dan maju. Ketentuan yang berlaku dalam penerapan metode invers kinematic mengacu pada panjang antar joint pada kaki robot, menentukan arah putaran dynamixel servo, menentukan batasan pergerakan sudut, dan konversi nilai sudut analisa metode invers kinematic ke nilai putaran dynamixel servo. Gerakan dibuat dengan menentukan arah putaran dynamixel servo seperti pada tabel IV.

Berdasarkan pembuatan alat ini dengan penerapan metode invers kinematic pada perancangan pergerakan jalan robot humanoid, masih banyak kekurangan yang terdapat pada alat. Untuk itu penulis akan memberikan beberapa saran dan masukan agar kedepannya alat ini bisa lebih baik lagi. Berikut saran dan tambahan dari penulis yang dapat dikembangkan, yang pertama pergerakan jalan pada robot ini masih dapat dikembangkan lebih lanjut lagi, juga dapat menggunakan servo yang berbeda. Selanjutnya, perhitungan proposional kerangka penyusun bodi robot (frame) sangat berpengaruh pada perge rakan jalan robot. Buatlah perhitungan proposional robot, serta gunnakan frame yang berbahan ringan agar robot lebih mudah untuk bergerak.

\section{REFERENSI}

[1] R. Andianto, R. Maulana, and G. E. Setyawan, "Perancangan dan Implementasi Sistem Pola Berjalan Pada Robot Humanoid Menggunakan Metode Inverse Kinematic," vol. 2, no. 8, pp. 2753 2760, 2018.

[2] A. R. Kurniawan and A. Triwiyatno, "Perancangan Robot Bipedal Dengan Sistem Berjalan Berbasis Inverse Kinematic Dengan Sensor Mpu 6050 Sebagai Indikator Kemiringan."

[3] S. Setiawan, Firdaus, B. Rahmadya, and Derisma, "Penerapan Invers Kinematika Untuk Pergerakan Kaki Robot Biped," no. November, pp. 1-9, 2015

[4] W. Budiharto and P. A. Nalwan, "Membuat-Sendiri-RobotHumanoid.pdf," Jakarta: PT Elexmedia Komputindo, p. 229.

[5] Mochamad Farid Mustofa, Sistem Pengaturan Keseimbangan Robot Humanoid Untuk Berdiri Dan Berjalan Pada Bidang Miring. 2016.

[6] A. A. Samarskij and P. N. Vabishchevich, Numerical methods for solving inverse problems of mathematical physics, vol. 52. 2007.

[7] Robotis, "BIOLOID Premium," ROBOTIS. 2019.

[8] U. W. Putri and Thamrin, "Perancangan Pergerakan Kaki Robot Humanoid Menggunakan Servo Dynamixel Berbasis Opencm 9.04," vol. 7, no. 2, pp. 1-9, 2019, doi: 10.2478/amsc-2014-0077.

[10] M. K. Wilis Kaswidjanti, S.Si., "Algoritma dan Pemrograman Function," Tek. Inform. Fak. Teknol. Ind. Univ. Pembang. Nas. "Veteran" Yogyakarta.

[11] T. G. S. Utami Afriyani Soraya; Ngilma, Nisa Latifatul; Surya B. Tito Garry; Dwi J., Raysita Galuh, "Jasa Pembuatan Dan Pengembangan Teknologi Robotika Sebagai Media Pembelajaran Pendidikan Menuju Indonesia Modern," Progr. Kreat. Mhs. Kewirausahaan, vol. 49, no. PKM-K 2013, pp. 1134-1140, 2013.

\section{Biodata Penulis}

Fuji Widia, lahir di Pasar Lansek Kadok, 02 Februari 1998. Menyelesaikan studi DIV Teknik Elektro Industri pada Jurusan Teknik Elektro Fakultas Teknik Universitas Negeri Padang.

Risfendra, S.Pd, MT, Ph.D, lahir di Riau, 1979. Sarjana Teknik Elektronika di Universitas Negeri Padang, lulus tahun 2004. Program S2 ditempuh pada Teknik Sistem Pengaturan, ITS Surabaya tahun 2008 dan S3 Shoutern Taiwan University of Science and Technology, Taiwan tahun 2017 dalam kajian robotik dan otomasi industri, teknik kontrol dan realisasinya pada rangkaian terpadu. Staf pengajar pada Jurusan Teknik Elektro FT UNP sejak tahun 2005-sekarang. 